Theoretical Study

\title{
Vital Energy and Afterlife: Implications for Cognitive Science of Religion ${ }^{1}$
}

\author{
Maira Monteiro Roazzi ${ }^{2}$ \\ Universidade Federal do Rio Grande \\ do Sul, Porto Alegre-RS, Brazil
}

\author{
Carl N. Johnson \\ University of Pittsburgh, \\ Pittsburgh-PA, United States of \\ America
}

\author{
Melanie Nyhof \\ Indiana University South Bend, South \\ Bend-IN, United States of America
}

\author{
Silvia Helena Koller \\ Universidade Federal do Rio Grande \\ do Sul, Porto Alegre-RS, Brazil
}

\author{
Antonio Roazzi \\ Universidade Federal de \\ Pernambuco, Recife-PE, Brazil
}

\begin{abstract}
Literature investigating people's concepts of supernatural agency (such as ghosts and deities) points to an intuitive theory of mind underlying such ideas, however, recent studies suggest that intuitive ideas over vital energy could also be involved. The present paper focuses on examining the culture and development of people's conceptions on vital energy. A search was made using the keyword vital energy targeting literature from Anthropology, Psychology and Cognitive Science. A literature review over this topic was made yielding reflections over the development of vital energy concepts. Results suggest that an intuitive biology, grounded on ideas of biological energy (vital energy), may underlie an understanding of soul, spirit, and supernatural energy. Future empirical studies should target the development of vital energy intuitive theories with different age ranges and cultures.
\end{abstract}

Keywords: vital energy, cognition, death and dying

\section{Energia Vital e Vida Após a Morte: Implicações Para a Ciência Cognitiva da Religião}

Resumo: A literatura que investiga conceitos acerca de agentes sobrenaturais apontam para uma teoria da mente intuitiva por trás de tais ideias, no entanto, recentes estudos sugerem a presença de teorias intuitivas acerca da energia vital subjacentes de tais conceitos. O presente artigo centra-se na análise da cultura e desenvolvimento das concepções das pessoas sobre a energia vital. Foi feita uma busca bibliográfica utilizando a palavra-chave vital energy, revisando literatura oriunda da Antropologia, Psicologia e Ciência Cognitiva. Em seguida, foi feita uma revisão sobre o tema tecendo considerações acerca do desenvolvimento das concepções das pessoas sobre a energia vital. Resultados apontam que uma biologia intuitiva, baseada em ideias de energia biológica (energia vital), pode ser a base de uma compreensão de alma, espírito e energia sobrenatural. Estudos empíricos futuros devem investigar o desenvolvimento de teorias intuitivas sobre energia vital com populações de diferentes faixas etárias e culturas.

Palavras-chave: energia vital, cognição, morte

\section{Energía Vital y Vida Después de la Muerte: Implicaciones Para la Ciencia Cognitiva de la Religión}

\begin{abstract}
Resumen: La literatura que investiga las opiniones de la gente sobre agentes sobrenaturales apunta a una teoría de la mente intuitiva detrás de esas ideas, sin embargo, estudios recientes sugieren la presencia de teorías intuitivas acerca de energía vital detrás de estos conceptos. Este artículo se centra en el análisis de la cultura y el desarrollo de las concepciones sobre energía vital. Se realizó una búsqueda bibliográfica con la palabra clave vital energy revisando literatura procedente de Antropología, Psicología y Ciencias Cognitivas. Se realizó una revisión sobre el tema con consideraciones sobre el desarrollo de las concepciones de energía vital. Los resultados muestran que una biología intuitiva, basada en las ideas de energía biológica (energía vital), puede ser la base de una comprensión del alma, el espíritu y el poder sobrenatural. Futuros estudios empíricos deben investigar el desarrollo de teorías intuitivas sobre energía vital con poblaciones de diferentes edades y culturas.
\end{abstract}

Palabras clave: energía vital, cognición, muerte

\footnotetext{
1 This paper is an output from the project undertaken as part of the Cognition, Religion and Theology Project at the University of Oxford, funded by the John Templeton Foundation.

Support: This work was also partially supported by a Graduate Fellowship (PDJ-Pós Doutorado Junior) granted by the National Council for Scientific and Technological Development (CNPq) to the first author (Grant no. 11550920/2012-1).

${ }^{2}$ Correspondence address:

Maira Monteiro Roazzi. Departamento de Psicologia - CFCH. Av. Arquitetura s/n, Cidade Universitária. CEP 50740-550, Recife-PE, Brazil. E-mail: maira.roazzi@gmail.com
}

Concepts that refer to vital energy are represented in many cultures. In India, it is referred to as prana, a life-sustaining force of living beings (Amritanshuram, Nagendra, Shastry, Raghuram, \& Nagarathna, 2013). In Afro-Brazilian religions it is referred to as axé, an invisible force that is magical and sacred and fundamental to all existence, both physical and spiritual (Cohen, 2007). In Chinese philosophy ch'i (qi) refers to an energetic fluid, which vitalizes the body, in particular as the breath, and 
which circulates outside us as the air (Edwards, Hlongwane, Thwala, \& Robinson, 2011).

In these and other examples, concepts of vital energy commonly cut across boundaries, affecting biological, mental, and spiritual conditions. These anthropological accounts suggest that concepts of vital force may be intuitive, widespread, and domain general.

The goal of this paper is to explore how an understanding of vital energy extends from a biological reasoning to spiritual thinking. More specifically, work in the field of Cognitive Science of Religion (CSR) will be reviewed, focusing on core concepts that emphasize an intuitive theory of mind as being the placeholder for beliefs in supernatural agency. Later a new approach emerging in the literature that challenges this focus on an intuitive theory of mind will be introduced (Cohen \& Barrett, 2011). This new theoretical view first emphasizes personhood (agency) as holding different elements, mainly mentality (Mind), vitality (Vital Energy) and identity (Essence). Second, it suggests that these components are typically combined in conceptualizing a person but may be activated in different ways depending on varying concepts, contexts, and cultures. Finally, building on this new theoretical approach, an intuitive understanding of vital energy as being at the core of people's intuitions of supernatural agency will be introduced, suggesting cross-cultural studies that explore the development of a causal-explanatory framework anchored on notions of vital energy.

\section{Vital Energy and the Cognitive Science of Religion}

The CSR field is centrally concerned with revealing the basic cognitive mechanisms that enable humans to develop religious beliefs and practices (Barrett, 2011; Boyer, 2001; McCauley \& Cohen, 2010). In this quest, empirical work has strongly converged to study what constitutes the basic cognitive underpinnings that drive belief in supernatural concepts. A wealth of studies have pointed out that these beliefs are initially anchored in intuitive concepts, that later extend to supernatural practices and beliefs (Boyer, 2001). Hence many studies in the field have set out to identify the specific core intuitive concepts that are at the root of such supernatural ideas, borrowing heavily from a theory-theory theoretical approach and from previous research in the field of cognitive development.

\section{Theoretical Positions in CSR: Supernatural Agency and Theory of Mind}

Traditionally, social science research on religion predominantly focused on observing and describing the seemingly endless variety of religious beliefs and practices across cultures and throughout history. The CSR discipline has developed a different approach, leaning towards the study of shared cognitive mechanisms (Bering, 2002).

The core idea is that religious concepts are understood as being the natural product of ordinary cognitive processes. Barrett (2011) described this perspective as the "naturalness-of-religion thesis' claiming that religion is explained by ordinary cognition plus the exposure to an ordinary environment. Thus the field of CSR is currently focused on three main issues: (a) how people represent supernatural concepts; (b) what are the intuitive cognitive foundations of these concepts and how they develop; and (c) how these intuitive concepts are later recruited in different cultural contexts.

Early theoretical elaborations in CSR focused on understanding what ties all seemingly discrepant manifestations of religious beliefs and practices together. Towards this end, Boyer (2001) has claimed that the common element that holds the diversity of religious and supernatural manifestations together is a belief in the existence of supernatural agents. Agents are defined as beings that possess mental features such as desires, beliefs, memories, intentions, and expectations whereas Supernatural Agents are depicted as beings that possess all such mental features, just like human agency, but that at the same time violate basic expectations of human agency, such as not possessing a physical body, or being able to fly and travel through walls. Boyer extends his claims by highlighting the attention grabbing potential of supernatural agents due to the fact that they violate basic expectations associated with our intuitive understanding of the world. Because agency is associated with mental characteristics, Boyer (2001) has claimed that "the only feature of humans that is always projected onto supernatural beings is the mind" (p. 163).

Given Boyer's theoretical claim, cognitive anthropologists and empirical psychologists set to investigate its validity. These studies have focused on two key aspects of Boyer's theoretical assumptions: First, on people's intuitions of supernatural agency; and second, if these intuitions were being driven by an intuitive theory of mind. Thus many studies began to look at people's intuitions of supernatural agents such as gods, ghosts (Barrett, 2011; Harris \& Giménez, 2005) and souls (Richert \& Harris, 2006, 2008). An underlying common goal of these studies was to ascertain if in fact people's intuitions of these agents were being driven by an implicit theory of mind. A selection of these studies is reviewed as follows.

\section{It's All About the Mind: A Case for an Intuitive Theory of Mind}

To illustrate work in CSR regarding people's intuitions over supernatural agents, empirical studies looking at the intuitions of children and adults over the afterlife will be initially presented. This research most clearly illustrates how an intuitive theory of mind readily provides the basis for inferences about the afterlife, depicting how the conceptions of the ordinary mind naturally lead to inferences about a disembodied life.

One of the widely cited studies in this area was performed by Bering and Bjorklund (2004). They asked North American children and adults to watch a puppet show in which an alligator eats a brown/white mouse. The mouse was presented as having 
characteristics that are biological (eating, drinking water, growing up), psychobiological (thirst, hunger, feeling sleepy or sick), perceptual (e.g., hearing, tasting, smelling, sight), based on desire (e.g., wishing, wanting hoping), emotional (sad, angry, scared) and epistemic (thinking, believing, knowing). Following the puppet presentation, participants were questioned about the continuity versus discontinuity of these biological, psychobiological, perceptual, desire-based, emotional, and epistemic functions after the mouse was eaten by the alligator, thus after it had died. Results indicated that younger children, between ages 4-6, overall tended to provide a stronger continuity pattern of responses, indicating more frequently that all functions continue after the mouse's death, while older children, between ages 6-8, and adults were more likely to assume the discontinuity of biological, psychobiological, and perceptual functioning in contrast to epistemic, emotional, and desire-based functioning. More specifically, however, young children's continuity answers were mainly driven by their intuitions on mental kinds, leading them to attribute continuity of mental functioning after death. In contrast, the discontinued answers given by older children and adults seem to be strongly guided by their intuitive and reflective ideas on biology, which override their previous intuitions on the continuity of mind. This happens because they have had more exposure to teaching about biological functioning and its implications regarding life sustainability. But even with this decrease, the results still pointed out that the discontinuity reasoning of older children and adults is more likely to be applied to mental states that are linked to the body (perceptual and psychobiological) than to other mental states that are easily detached from the body (epistemic, emotional, and desire-based). These findings show that children and adults tend to infer the existence of mental functioning to agents even after their death, that is, even after they don't possess a functioning body. The degree and the selective mental properties that are projected may vary with age, but nevertheless, participants still assumed that the dead mouse held some sort of mental functioning after death.

In another study, Bering (2002) looked at how participants' explicit afterlife beliefs (i.e., extinctivist, agnostic, immortalist, reincarnationist, eclectic, and other believers) influence their intuitions of the continued functioning of biological, psychobiological, perceptual, desire-based, emotional, and epistemic states after death. In an interview designed to elicit implicit intuitions, undergraduate students were questioned on whether a set of mental and biological properties continue after a character is killed in an accident. Results show that "those who believe in some form of life after death (and, to a certain extent, even those who do not) implicitly represent dead agents' minds in the same way: psychobiological and perceptual states cease while emotional, desire, and epistemic states continue" (Bering, 2002, p. 263). Even participants that described themselves as "extinctivists" (i.e., personal conscience ceases with death) showed a tendency to attribute more continuity to epistemic, emotional, and desire-based states, as compared to biological, psychobiological, and perceptual states. This study showcases how one's reflective ideas concerning the discontinuity of all functioning after death, might be overridden by mind intuitions, giving rise to implicit assumptions of continuity of some mental functioning after death.

In another line of research, Harris and Giménez (2005) have reported that people appear to commonly operate with two different perspectives about death: a secular perspective in which death involves the cessation of all bodily and mental functions; and a metaphysical perspective, in which death is conceived as a metamorphosis, where bodily life discontinues and a new life begins that is not constrained by biological processes. These different perspectives on death appear to be distinctly elicited in different contexts. Thus, Harris and Giménez (2005) presented two narratives (secular and religious) to a group of 7- and 11-year-olds, from a public school in an urban city in Spain. The secular narrative described the death of a grandparent in a secular/medical context and the religious narrative described death in a metaphysical/religious context. After each story, children were asked to judge and justify the functioning or non-functioning of various bodily and mental processes after the grandparent's death. Children were more likely to judge that certain processes continue after death when they were questioned in the context of the religious as opposed to the secular narrative. They were also more likely to claim that mental processes continue functioning after death as compared to bodily processes, regardless of the narratives presented. The results showed that both age groups hold a dual conception of death as a biological endpoint on the one hand, and as a metaphysical transformation on the other.

To see if this pattern held up in a different cultural setting, Astuti and Harris (2008) conducted a similar study with Vezo tribes in rural Madagascar. They tested children, from 8- to 17-years-old, and adults from 19- to 71-years-old. Participants were presented to a secular (corpse) narrative and a religious (tomb) narrative, where a character dies. They were then asked whether bodily and mental processes continue after death. Participants often claimed that processes cease at death (discontinuity theory of death), however such claims were more frequent for bodily processes than mental processes, and more frequent among the secular narrative (i.e., the corpse narrative) than with the religious narrative (i.e., the tomb narrative). This pattern was consistent across the different age groups. Similar results were also observed by Roazzi, Dias, and Roazzi (2010) on a replication of this study in Brazil.

Literature looking at the reasoning of children and adults about the afterlife, that is, about the nature of dead agents (such as ghosts) seems to indicate that an implicit theory of mind is projected onto the inferences they make about these supernatural agents. The evidence presented supports the view that human beings are naturally intuitive dualists. According to Bloom (2004), Cartesian dualism assumes a crucial distinction between res extensa, our 
physiological machinery, and res cogitans, which refers to our minds and our thoughts. In other words, "we use our bodies to experience and act on the world, but we ourselves are not physical things, we are immaterial souls" (Bloom, 2004, p. 11). Bloom advanced his argument by stating that we are natural Cartesians and that due to this fact dualistic thinking comes naturally to us, making us think of bodies and minds as distinct (Bloom, 2004). On this basis, not only do we process God and ghosts using an implicit theory of mind, but also concepts of soul and spirit are similarly viewed as essentially derivative of the concept of mind (Bering \& Bjorklund, 2004; Bloom, 2004).

Cohen and Barrett (2008) took this argument a step further to give an account of spirit possession. They wanted to explore possible cognitive factors influencing the cross-cultural incidence of spirit possession concepts, to gain a more refined understanding of an intuitive mind-body dualism in terms of a supernatural kind of action. Towards this end, Cohen and Barrett looked at how English undergraduate students reason about the effects of a hypothetical mind-migration across a set of behaviors. These behaviors consisted of behavioral judgments that hinge heavily upon physical and not mental aptitudes (e.g., appetite, strength, speed, visual acuity) contrasted with behavioral judgments not tightly anchored to particular physical attributes (e.g., math competency, sociability, emotionality). They presented participants with a set of hypothetical mind-transfer scenarios in which the mind of one person (A) is transferred into the body of another person (B), the host. Participants were asked to reason about the new post-transfer person's behaviors and aptitudes. The results showed that the majority of participants reasoned that while the post-transfer person's performance on physical tasks (e.g., sprinting) would be similar to the host's (B), whereas the performance on mental tasks (e.g., math) would be similar to the person whose mind had been transferred (A). Thus mental characteristics seem to be attributed to the incoming agent, while characteristics that are physical in any way are attributed to the host's body, implying that physical aptitudes aren't implicitly assumed to travel during the migration. Moreover, participants overwhelmingly assumed the mind to transfer completely (all or nothing) instead of partially. Thus one gets the whole mind as a package.

This data lines up with Bloom's claim of Cartesian dualism; once participants clearly distinguished mental from bodily behaviors and aptitudes, transferring the mental, and not the bodily attributes. In addition, participants tended to infer a complete displacement of minds, such that the post-transfer person's performance on mental task items was reasoned to be identical to incoming person's performance. On this basis, they hypothesized that spirit possession is naturally conceived as mind possession, consisting of a complete displacement of mind properties from one body to another.

Up to this point, the dominant view is that that the ontology of immaterial agents commonly emerges from an intuitive theory of mind. Considerable evidence reviewed above supports the view that human beings are naturally intuitive dualists, which provides the basis for imagining the possibility of mind as a mental-causal organization functioning independent of the physical-causal constraints of the body. On this basis, concepts of soul and spirit are viewed as essentially derivative of the concept of mind (Bering \& Bjorklund, 2004; Bloom, 2004).

\section{More Than Mind: A Case for Soul and Spirit}

In spite of the empirical evidence that points to a theory of mind as being the underlying intuitive base that drives inferences of supernatural agency, recent work in the field has suggested that there is something more than mind at the heart of religious conceptions. This suggestion was first raised in studies on adults and children's intuitions of soul. The assumption in the field was that the concept of soul was basically grounded in an intuitive understanding of mind. Questioning this assumption, Richert and Harris (2006) compared children's inferences about the soul with their inferences about the mind and brain. They asked children how mind, brain, and soul are affected by a religious ritual (baptism) and how different kinds of functioning - cognitive, non-cognitive, and biological - would continue without the presence of the mind, brain, and soul. Their results indicate that children believed mind and brain change and grow over time, in contrast, the soul remains constant and is devoted to predominantly, spiritual functions (i.e., moral purpose, connecting to the divine life-giving force both in life and afterlife, and love). In a second study, Richert and Harris (2008) explored adult's conceptions of the ontological and functional properties of the mind as compared to the soul. The existence of the mind was generally tied to the human lifecycle of conception, birth, growth, and death, and was primarily associated with cognitive (i.e., problem solving, thinking, telling right from wrong, memory) as opposed to spiritual functions (i.e., life force, afterlife, connection to higher power, spiritual essence). In contrast, the existence of the soul was less systematically tied to the lifecycle and frequently associated with spiritual as opposed to cognitive functions.

Based on their findings, Richert and Harris $(2006,2008)$ have argued that the concept of soul develops independently from the concept of mind, claiming that children and adults conceive of the soul more as the enduring essence of a person, while mind consists of changing mental competences.

Just as the concept of soul does not appear to reduce to the concept of mind, Roazzi, Nyhof, and Johnson (2013) have proposed that the concept of spirit may have still other intuitive roots. Cohen and Barrett (2008), in their work on spirit possession, argued that it is intuitively processed as a mind possession, thus equating mind to spirit. In contrast, Roazzi et al. (2013) argued that the concept of spirit originally refers to the vital force of life. In this account, 
spiritual ideas do not primarily emerge from concepts of mind and agency, but from concepts of life and energy. This definition is shared by many religious and philosophical traditions, but it doesn't mean that people readily conceive the spirit in this fashion. Anthropological accounts also portray people's concepts of spirit as being similar to that of a supernatural agent, such as a ghost (Cohen, 2007). To examine these differences Roazzi et al. (2013) tested adult's inferences about mind and soul as well as spirit. Their study was the first to compare intuitions about these three concepts together in the context of considering how different cultures and religions may recruit similar or different intuitive ideas. Methodologically, the study was built on the hypothetical transplant/transfer methods employed in previous research (Cohen \& Barrett, 2008). Undergraduate students from Brazil, Indonesia, and the USA were presented with a series of conditions where one character's soul, mind, or spirit transfers to the other character's body. These different conditions involved the transfer of different attributes of human functioning - cognitive, bodily, social, and moral. Given the dual interpretation of spirit as being either an agent (mental kind) or a vital energy (vital kind), characters initially differed in either a level of ability (i.e., skill) or level of passion (i.e., energy) for the attribute being transferred. Participants were then asked to judge if the transfer yielded either a complete, partial, or no transfer of the highlighted attribute being measured. The results point to differences as well as considerable overlap of participants' conceptions of mind, soul and spirit, along with influences of culture and religion. Across countries, the mind tended to be more associated with ability and cognitive attributes, while soul and spirit were relatively more associated with passion and social and moral attributes. These findings are consistent with Richert and Harris (2006, 2008), who also reported evidence of the mind being more associated with cognitive abilities, while the soul was more associated with moral and spiritual qualities. In addition, soul and spirit were more distinctly related to religious influences. However, spirit was not distinctly associated with passion (energy). Instead, the data suggest that passion/energy is equally an integral part of concepts of mind, soul, and spirit. The authors concluded that the three disembodied agents - soul, mind, and spirit - held both a mental dimension and an energy dimension.

These findings, along with findings reported by Richert and Harris $(2006,2008)$, seem to point to a yet richer set of intuitive origins that involve not only a basic intuitive theory of mind, but also involve intuitions pertaining essence and energy.

The goal of this paper is to examine the development of an intuitive understanding of vital energy (vitalism) further exploring how it extends to spiritual thinking. However in order to advance towards this goal, it is important to first grasp a better understanding of what this reasoning process evokes. Roazzi et al. (2013) revealed that intuitions on energy don't necessarily hold a one to one correspondence to either mind, soul, or spirit. In addition, the authors claim that their results were limited to the language terminology that they used, as they come to capture these terms. Furthermore, their measure of energy was limited, focusing only on a persons' personal engagement in a given activity. Results yielded from Roazzi et al. (2013) raise deeper questions about what vital energy is, how it is conceptualized, and how it should be studied, thus calling for a more careful look at the concept of vital energy (versus spirit) as it is represented across cultures.

The following is a short review of how this concept is and has been represented in different historical and cultural contexts. Information yielded from this review will illustrate how people seem to think about energy in different cultural contexts, hence facilitating a later assessment of its developmental origins in early cognitive development.

\section{Vital Energy - Across Time and Cultures}

Concepts that refer to vital energy aren't new to humankind. These concepts have been represented in many cultures and across time in ways that are culturally significant and appropriate. In Chinese philosophy ch' $i$ (qi) refers to an energetic fluid, which vitalizes the body, in particular as the breath, and which circulates outside us as the air (Edwards et al., 2011).

The concept of qi has a wide array of interpretations and usages (Mayor \& Micozzi, 2011). Despite this variability, $q i$ is recurrently referred to as a breath or vapor, as a creative force, as divine flow, that comes to embraces multiple properties, such as physical, psychic, emotional, spiritual, and even mystic properties (Roazzi, 2012). In everyday life, qi is to be cultivated and/or accumulated in order to achieve enlightenment and a long life (Mayor \& Micozzi, 2011). As an example, breathing techniques, meditation and martial arts (such as Tai chi chuan) are ways in which one can heighten qì force.

Comparable to the Chinese notion of $q i$ is the Indian Ayurveda concept of prana, conceived as a vital, life-sustaining force of living beings that is believed to flow through a network of fine subtle channels in one's body (Amritanshuram et al., 2013). One can cultivate prana with the practice of yoga, meditation, and breathing techniques. The Ayurveda representation of prana seems to endow it with properties that influence one's physical, mental, and spiritual well-being.

In Afro-Brazilian religions we find yet a different representation of the vital energy principle, named axé. African slaves that came from Yoruba traditions brought this concept to Brazil. It is defined as an invisible force that is magical and sacred and fundamental to all existence, both physical and spiritual (Cohen, 2007). Axé can be sowed, cultivated, shared, used (spent), and even renewed. To receive axé, means to incorporate material and symbolic representations of the vital principle both from a physical world (aiye) as well as its correlates from a spiritual world 
(orun), meaning there is always a constant interplay of axé between both worlds. In the physical world, axé is energy that can be found in the animal (e.g., human and animal blood), vegetal (e.g., dendê oil and honey), and mineral (e.g., copper, bronze, and gold) kingdoms. Thus Afro-Brazilian religious groups, such as Candomblé and Umbanda, describe axé as a magical force that acts upon not only one's biological health, but also one's spiritual and psychological well-being.

Finally, in Inca culture, there are two terms referring to energy, hucha, a heavy, dense black energy, and sami, a high frequency, light, subtle energy that comes from being in harmony with the universe (Dollman, 2013). According to Roazzi (2012) Sami is permeated in the natural world, animating all living beings and passing on 'power' to natural objects and places where it accumulates. An increased amount of Sami in one's body is correlated with a life of harmony and well-being with others and the natural world. Hucha, in contrast, is created by human beings, naturally accumulated through human action and interaction and human emotions. Accumulation of hucha energy is not desired because it affects ones physical, emotional, mental, and spiritual states. As an example, when someone became sick they were assumed to be full of hucha, acquired due to selfish attitudes. A high amount of hucha does not allow the flow of sami in one's body, leading the person to become physically sick. In this case, the energy of human agency (hucha) is sharply contrasted with vital energy (sami). The examples depict the different ways in which cultures seem to recruit thinking in terms of vital energy, thus generating these diverse representations. As proposed by CSR, there is a common intuitive core underlying this variety of ideas. It is not clear what this common intuitive core is, but what can be drawn from these examples is that in spite of cultural diversity, peoples' concepts of vital energy are being elicited to understand/explain biological, psychological, and spiritual processes.

To advance further understanding of vital energy, theory and research need to target three core issues: (a) what are the intuitive foundations of people's concept of vital energy?; (b) how do these concepts develop?; (c) how or when does one's cultural environment recruit these intuitive ideas to later generate a reflective concept of vital energy?

The first two issues target the underlying intuitive foundation of concepts of vital energy and its development. Literature looking at children's understanding of vital energy is scarce, and the work available seems to highlight vital energy as a concept that is inherently part of the domain of biology. Research on children's understanding of vital energy emerged in the field of cognitive development, specifically in literature looking at children's naïve biology. Two Japanese psychologists, Kayoko Inagaki and Giyoo Hatano, initiated this research agenda. In their investigations on how children reason in the domain of naive biology, Inagaki and Hatano (2002) claimed that young children possess a causal-explanatory framework exclusively grounded in naïve biology. This causal-explanatory mechanism received the name of vitalistic causality and is portrayed as being an implicit or intuitive theory children come up with in order to explain biological phenomena. Research from the field of naïve biology suggests that young children reason in terms of vital force or vital energy as an unidentified energy that is an integral part of biological functioning (Inagaki \& Hatano, 2002). Literature has also shown that later in development children substitute vitalistic causality as a whole for more culturally appropriate causal-explanatory mechanism, i.e., mechanistic causality, which is grounded on today's scientific rationale (Schlottmann, Cole, Watts, \& White, 2013). The question that remains unanswered is whether thinking in terms of vitalistic causality is dropped completely or if it is shifted or recruited to explain other kinds of phenomena that aren't biological in nature.

\section{Putting Things Together}

Past theory and research in CSR was built on the notion of an implicit theory driving people's intuitions on supernatural agency. Studies looking at beliefs in afterlife and spirit possession have narrowly focused on demonstrating that people rely on an intuitive theory of mind when reasoning about supernatural agency. Results from these studies succeeded in supporting this conclusion. New advances in the field that tried to detach from this narrow focus, found that there seems to be other intuitive domains involved on peoples reasoning over supernatural agency, such as an intuitive understanding of essence and vital energy.

Given these new findings, a shift in the direction of future theory and research was necessary. Thus a new agenda in the field of CSR, seeking to account for other intuitive domains associated with intuitions on supernatural agency, was proposed by Cohen and Barrett (2011). This new agenda for framing future studies in this field, focuses not necessarily on agency per se, but reframes it in a more holistic way, highlighting the nature of personhood as being at the core of peoples intuitive reasoning about supernatural agents and human agency in general. This new theoretical view first emphasizes personhood as holding different elements, especially mentality (mind/agency), vitality (vital energy) and identity (essence). Intuitions on mentality would be anchored on intuitive psychology (theory-of-mind), intuitions on vitality would be anchored on intuitive biology and intuitions on essence would be anchored on some sort of essentialist or biological intuitive theory. Second, the authors suggest that these components are typically combined in conceptualizing a person but may be activated in different ways depending on varying concepts, contexts and cultures. Thus, cultural settings will influence the recruitment of different patterns of personhood. This would explain why some people might process the concept of spirit as operating solely in their intuitive domain of biology, viewing it as a vital force of life that sustains biological functioning, while others might process the concept of spirit as being an agent, 
associating it to a ghost, activating possibly their intuitive domain of biology and psychology simultaneously.

In order to advance knowledge in the field of CSR it is important to gain a better understanding of these proposed components of personhood. There is a developed research agenda looking at the component of mentality (Bering \& Bjorklund, 2004; Harris \& Giménez, 2005) and some new advances have been made looking at intuitions on personal essence (Richert \& Harris, 2006, 2008). However there is a limited amount of work addressing the component of vitality. The field's ultimate goal is to study what role do intuitions about vital energy play on how people process supernatural concepts. Though, before advancing research in that direction, it is important to first understand the origins and development of a concept on vital energy, further investigating how they are later recruited in different cultural contexts.

Building on work reviewed so far, this paper aims to set the framework for future research on vital energy, addressing core issues. As a first step, it's important identify what early concepts of vital energy look like. Are these early concepts founded in an intuitive biology? Or are these concepts used to explain phenomena across domains from the beginning?

Furthermore, it is important not only to study people's concepts on vital energy early in life, but also look at its development. Thus future methodologies should target various age groups, making use of either cross-sectional or longitudinal designs, to investigate how these intuitions change throughout development, and what the factors are that might affect this process.

To address the question of whether a concept on vital energy starts of as bounded to a naïve biology, or if it is recruited to explain phenomena in various domains, one of the first objectives of future research in this field lies in exploring if reasoning in terms of energy transfer/flow (not organ intentionality) extends beyond the domain of biology, and specifically if and at what stage of development it extends to the domain of psychology.

Finally, the anthropological examples suggest that adults later in life reason reflectively about vital energy across domains; however this claim remains to be tested empirically. In testing this, adults' reflective and intuitive concepts on vital energy should be targeted, enabling a comparison of how different cultures recruit these ideas, highlighting similarities and differences. Furthermore, given that CSR is invested in understanding what common core culture recruits from, an additional question concerns if culture is in fact recruiting from basic intuitions when eliciting these ideas.

In studying the development of this concept, what are other things we need to know about vital energy? Two key questions are: what is the source of vital energy? and what does it affect? In both cases it is necessary to study the domain from which this vital energy is assumed to come from and the domain it is affecting. Past research (Inagaki \& Hatano, 2002) has been limited to studying vital energy originating from sources such as rest, food, and water, affecting ones biological body. Given the review of examples of how different groups of people reason about vital energy, it makes sense to advance studies on vital energy affecting ones biological and psychological, as well as spiritual well-being.

Furthermore, vital energy has been portrayed in different cultural settings as originating from different sources. In an attempt to organize this knowledge, one could assume that these sources can be natural, self-psychological, social-psychological and spiritual. As an example, natural sources of vital energy are air (through breathing), food, sunshine, and water. $Q i$ and prana are examples of how some cultures represent energy as coming from these natural sources. Self-psychological sources of vital energy can be represented as activities that somehow "vitalizes you", such as exercising your body or maintaining good thoughts. As an example, hucha for the Incas represented a negative valence of vital energy that was generated by, for example, selfish thoughts and actions. Social-psychological sources of vital energy can be represented as activities in which someone receives energy from another person. For Afro-Brazilian religions, one can receive positive vital energy from another person by means of speech. Finally, spiritual sources of energy could come from activities that imply some connection with a higher reality, such as praying, meditating, and drinking holy/blessed water.

To know from which domain adults and children assume vital energy to come from as well as what they assume it is going to affect, future studies should address this issue carefully. These studies need to examine not only what people assume the origins of the vital energy to be, as well as whether they assume one source as more charged with energy than others. Furthermore, it is possible that children and/or adults are significantly more likely to recruit certain sources of vital energy for specific targeted effects, possibly assuming that natural sources of vital energy only affect the physical body, whereas social-psychological sources of energy hold the capacity to affect both the physical body as well as one's psychological state. Finally, this study should be framed in a way that explores how these reasoning processes may vary across cultures.

Results stemming from this developmental line of research, targeting both children as well as adult populations, would yield a better understanding of how this thought process develops, and if people assume it affects ones mental, bodily and/or spiritual well-being. If it is assumed to affect the mental/psychological as well as the spiritual domain, this could lead to potential new insight on how people reason intuitively about supernatural kinds.

This research would yield more empirical data to support Cohen and Barrett's component view of personhood as implicitly guiding people's intuitions on supernatural agency. This would provide a better understanding of the assumption that personhood likely entails multiple intuitions of immaterial kinds (including inferences about agency, 
energy, and essence), and how these intersect on people's intuitions over terms like mind, soul, and spirit, as they inhabit the same conceptual space of immaterial identity.

\section{References}

Amritanshuram, R., Nagendra, H. R., Shastry, A. S. N., Raghuram, N. V., \& Nagarathna, R. (2013). A psychooncological model of cancer according to ancient texts of yoga. Journal of Yoga \& Physical Therapy, 3, 129. doi: $10.4172 / 2157-7595.1000129$

Astuti, R., \& Harris, P. L. (2008). Understanding mortality and the life of the ancestors in rural Madagascar. Cognitive Science, 32(4), 713-740. doi:10.1080/03640210802066907

Barrett, J. L. (2011). Cognitive science, religion, and theology: From human minds to divine minds (Templeton Science and Religion Series). West Conshohocken, PA: Templeton.

Bering, J. M. (2002). Intuitive conceptions of dead agents' minds: The natural foundations of afterlife beliefs as phenomenological boundary. Journal of Cognition and Culture, 2(4), 263-308. doi:10.1163/15685370260441008

Bering, J. M., \& Bjorklund, D. F. (2004). The natural emergence of reasoning about the afterlife as a developmental regularity. Developmental Psychology, 40(2), 217-233. doi:10.1037/0012-1649.40.2.217

Bloom, P. (2004). Descartes' baby: How the science of child development explains what makes us human. New York, NY: Basic Books.

Boyer, P. (2001). Religion explained: The evolutionary origins of religious thought. New York, NY: Basic Books.

Cohen, E. (2007). The mind possessed: The cognition of spirit possession in an Afro-Brazilian religious tradition. New York, NY: Oxford University Press.

Cohen, E., \& Barrett, J. (2008). When minds migrate: Conceptualizing spirit possession. Journal of Cognition and Culture, 8(1-2), 23-48. doi:10.1163/156770908X289198

Cohen, E., \& Barrett, J. L. (2011). In search of 'folk anthropology': The cognitive anthropology of the person. In J. W. van Huyssteen \& E. P. Wiebe (Eds.), In search of self: Interdisciplinary perspectives on personhood (pp. 104-124). Grand Rapids, MI: Wm. B. Eerdmans.

Dollman, J. (2013). Living Shamanism: Unveiling the mystery. New Alresford, United Kingdom: Moon Books.

Edwards, S., Hlongwane, M., Thwala, J., \& Robinson, N. (2011). Indigenous patterns of energy healing with special reference to Africa, India and China. Indilinga: African Journal of Indigenous Knowledge Systems, 10(1), 39-52.

Harris, P. L., \& Giménez, M. (2005). Children's acceptance of conflicting testimony: The case of death. Journal of Cognition and Culture, 5(1-2), 143-164. doi:10.1163/1568537054068606
Inagaki, K., \& Hatano, G. (2002). Young children's naive thinking about the biological world. New York, NY: Psychology Press.

Mayor, D. F., \& Micozzi, M. S. (2011). Energy medicine East and West: A natural history of QI. Edinburgh, United Kingdom: Churchill Livingstone Elsevier.

McCauley, R., \& Cohen, E. (2010). Cognitive science and the naturalness of religion. Philosophy Compass, 5(9), 779-792. doi:10.1111/j.1747-9991.2010.00326.x

Richert, R. A., \& Harris, P. L. (2006). The ghost in my body: Children's developing concept of the soul. Journal of Cognition and Culture, 6(3), 409-427.

Richert, R. A., \& Harris, P. L. (2008). Dualism revisited: Body vs. mind vs. soul. Journal of Cognition and Culture, 8(1), 99-115. doi:10.1163/156770908X289224

Roazzi, M. (2012). Vital energy: The development of a core concept (Unpublished doctoral dissertation). University of Pittsburgh, Pittsburgh, PA.

Roazzi, M., Nyhof, M., \& Johnson, C. N. (2013). Mind, soul and spirit: Conceptions of immaterial identity in different cultures. The International Journal for the Psychology of Religion, 23(1), 75-86. doi:10.1080/10508619.2013.735504

Roazzi, M. M., Dias, M. B. B., \& Roazzi, A. (2010). Mais ou menos morto: Explorações sobre a formação do conceito de morte em crianças. Psicologia: Reflexão e Crítica, 23(3),485-495. doi:10.1590/S0102-79722010000300009

Schlottmann, A., Cole, K., Watts, R., \& White, M. (2013). Domain-specific perceptual causality in children depends on the spatio-temporal configuration, not motion onset. Frontiers in Psychology, 4, 365. doi:10.3389/fpsyg.2013.00365

Maira Monteiro Roazzi is a Postdoctoral Research Fellow in the Universidade Federal do Rio Grande do Sul.

Carl N. Johnson is an Associate Professor in the School of Education, University of Pittsburgh.

Melanie Nyhof is a Postdoctoral Research Fellow in the Indiana University South Bend.

Silvia Helena Koller is a Full Professor of the Universidade Federal do Rio Grande do Sul.

Antonio Roazzi is a Full Professor of the Universidade Federal de Pernambuco.

Received: June 8, 2014

1st Revision: Oct. 17, 2014

Approved: Dec. 1, 2014

How to cite this article:

Roazzi, M. M., Johnson, C. N., Nyhof, M., Koller, S. H., \& Roazzi, A. (2015). Vital energy and afterlife: Implications for cognitive science of religion. Paidéia (Ribeirão Preto), 25(61), 145-152. doi:10.1590/1982-43272561201502 